\title{
Sine and Cosine Generator and FIR Filter Designing based on CORDIC Algorithm
}

\author{
Shalini Rai \\ Department of Electronics \&Communication \\ University of Allahabad
}

\author{
Rajeev Srivastava \\ Department of Electronics \& Communication \\ University of Allahabad
}

\begin{abstract}
Field Programmable Gate Array (FPGA) technology is the popular platform for the designing of higher speed of algorithms which are used in the field of the signal processing. There are various applications which are designed by the scientist on the FPGA platform such that digital filters, their sampling rates are more than the available digital filter DSP chip. FPGA implemented digital filter has higher flexibility, low cost than the available DSP chips. In Digital signal processing area and VLSI technology there are various algorithm for the production of the high speed VLSI different circuits. Among these the CORDIC algorithm [1,5] is most popular for the designing of the high speed VLSI architecture. For the reduction of occupied space and energy consumption we design the scale free CORDIC architecture.

This paper proposed a CORDIC pipelined architecture. By this architecture we compute the sine cosine function, and also we design the high pass FIR Filter by using VHDL language. The sine cosine generator and high pass FIR filter have synthesized by using typical and scale free CORDIC algorithm. These designing are simulated and tested on FPGA Virtex 4 device. These codes have synthesized using Xilinx ISim 13.1 simulator software. We also discuss about the total energy consumption, plot of output of the Filter and their analysis. Give the relative examination of the typical CORDIC algorithm and scale free CORDIC algorithm based designing.
\end{abstract}

\section{General Terms}

CORDIC Algorithm, Filter Designing.

\section{Keywords}

Scale free CORDIC Algorithm, Finite Impulse Response Filter, and High Pass Filter.

\section{INTRODUCTION}

The task termed as Filtering is the procedure for extracting of the signals for the particular applications. In VLSI technology the fast digital filters are designed on the FPGA. In the last five to ten decades the CORDIC algorithm is the very eminent algorithm to producing the fast VLSI implementations. It is a productive and capable hardware algorithm to optimizing the area, speed, power and hardware cost. The typical CORDIC (Coordinate Rotation Digital Computer) algorithm is designed by Jack.E.Volder, which is a 3-D rotational vector algorithm. In 1971 unified CORDIC algorithm [2, 6] was invented. It is used in hyperbolic, linear, circular coordinates systems for the computations of several trigonometric functions, hyperbolic function and logarithmic functions of real and complex numbers. For reducing the number of iterations there are abundance of advancements in

CORDIC algorithm, like the angle-recording (AR), modified vector rotation, mixed scaling rotation (MSR) and scaling free CORDIC algorithms. These algorithms have been improving the system performance and speed. In this paper we have discussed about the typical, scale free CORDIC algorithm, CORDIC Architecture [3, 4], FIR filter in section II, III, IV respectively. In section V we have to deal with designing of sine cosine generator \& FIR filter based on typical CORDIC algorithm and scale free CORDIC algorithm. In section $\mathrm{V}$ we discuss about sine cosine generation by using typical CORDIC algorithm and scale free CORDIC algorithm, total energy consumption, plot of output of the Filter, and comparative analysis of typical and scale free CORDIC algorithm based designing.

\section{THEORY OF CORDIC ALGORITHM}

The algorithm is defined in such a way that it is an iterative sequence of additions or subtractions and shift operations are used in two different fashion, rotation and vectoring. In the algorithm vector are rotated by a fixed rotation angle in three different coordinate system, circular, linear and hyperbolic system.

\subsection{The Typical CORDIC algorithm}

is in the general rotation transform-

$x 1=x \cos \alpha-y \sin \alpha$

$y 1=x \sin \alpha+y \cos \alpha$

The above equations can readjusted as

$$
\begin{aligned}
& x 1=[x-y \tan \alpha] \cos \alpha \\
& y 1=[y+x \tan \alpha] \cos \alpha
\end{aligned}
$$

These rotation of angles are represented so as $\tan \alpha= \pm 2^{-i}$. The tangent multiplication is reduced by simple shift operation. The angle $\alpha$ divided into elementary rotation angle in a sequence manner.

$$
\alpha=\sum \alpha i
$$

So iterative equations of CORDIC Algorithm are

$x i+1=[x i-y i \tan \alpha i] \cos \alpha i$

$y i+1=[y i+x i \tan \alpha i] \cos \alpha i$

For the trigonometric identities

$\cos \alpha i=1 / \sqrt{1+\tan \alpha i^{2}}$

Replace the term $1 / \sqrt{1+\tan \alpha i^{2}}=k i$

or $k i=1 / \sqrt{\left(1+2^{-2 i}\right.}$

ki denotes as constant multiplication factor .The gain is 
defined as the inverse of the constant multiplication factor.

$$
A i=1 / k i
$$

The system gain

$A n=\Pi\left[1+2^{-2 i}\right] \approx 1.647$

So the above equation no. (6) and (7) becomes

$x i+1=k i\left[x i-y i . d i .2^{-i}\right]$

$y i+1=k i\left[y i+x i \cdot d i .2^{-i}\right]$

di is the decision function depends the rotational mode. First is the rotation mode and second is the vectoring mode

a) For the rotation mode

$d i=-1$ if $z i<0$

di $=+1$ if else

After $\mathrm{n}^{\text {th }}$ iteration it produces the following results

$x n=A n[x 0 \cos z 0-y 0 \sin z 0]$
$y n=A n[x 0 \sin z 0+y 0 \cos z 0]$
$z n=0$

b) For vectoring mode

$d i=+1$ if $y i<0$

$=-1$ else

After $\mathrm{n}$ iteration it produces the following results

$x n=A n \sqrt{\left[\left(x 0^{2}\right)+\left(y 0^{2}\right]\right.}$

$z n=\tan ^{-1}(y 0 / x 0)+z 0$

$y n=0$

\subsection{Scale Free CORDIC Algorithm}

The improvements of CORDIC algorithm are very important aspect. There are disparate developments of the CORDIC architectures for high performance and for reduction of the cost. Pipelined and parallel CORDIC architectures are suitable for the high throughput. For high performance and high throughput, radix -2 with constant scale factor using signed digit(SD) arithmetic and carry save arithmetic(cs) are used in CORDIC algorithm, such as double rotation, correcting rotation, branching method, double step branching, differential methods are used.

Radix-4 based CORDIC algorithm is also used for the enhancement of the speed of the CORDIC architectures. By using radix-4 the no of iterations of the CORDIC algorithm are also reduced. It has been developed and reported in the literature by antelo et.al. and lakshmi. Radix -4 based CORDIC architectures [7, 8, and 9] has been occupied larger area and required higher computational time. There are two main directions for the improvements of the CORDIC algorithm (i) higher Radix (b) Scaling factor. It is very important that the CORDIC architectures are designed in such a way that the CORDIC architecture speed is very high but the no of iteration has also been decreased. From last five decades there are some improvements in CORDIC algorithm like scaling free CORDIC algorithm, enhanced scaling free CORDIC algorithm and virtually scaling free CORDIC algorithm. The scaling-free CORDIC algorithm is designed by using the taylor series approximation method, but the area consumption will be increased in this method. The enhanced scale-free CORDIC is the combination of the typical CORDIC algorithm with scaling -free CORDIC algorithm. However this type of mechanism weakens the potential and capability of the system. Virtually modified scaling-free algorithm improves the range of target of the angle over the entire coordinate symmetry.

\section{CORDIC ARCHITECTURE}

(a)CORDIC ARCHITECTURE: The two main parts of the CORDIC Architecture

(i) Folded

(ii) Unfolded

Folded architecture has two parts Serial and word Serial Unfolded architecture has two parts Pipelined and parallel. In this project we use the pipelined architecture.

First of all we use scaled pipelined architecture, and then scale free pipelined CORDIC architecture.

(b)Scaling-free CORDIC $[10,11]$ is initially designed by using Taylor-series. The sine and cosine approximated to

$$
\begin{aligned}
& \sin \alpha i=2^{-i}, \\
& \cos \alpha i=1-2^{-(2 i+1)}
\end{aligned}
$$

Taylor series expansion allowed the rotation only in one direction compared to typical CORDIC.

The taylor series of sine and cosine terms defined as

$\sin \alpha i=\sum_{n=0}^{\infty}(-1)^{n} \frac{\alpha i^{2 n}}{! 2 n}=1-\frac{\alpha i^{2}}{! 2}+\frac{\alpha i^{4}}{! 4}+$

$\cos \alpha i=\sum_{n=0}^{\infty}(-1)^{n} \frac{\alpha i^{2 n+1}}{! 2 n+1}=\alpha i-\frac{\alpha i^{3}}{! 3}+\frac{\alpha i^{5}}{! 5}+---$

The suggested algorithm used third order expansion and approximate 3 ! To $2^{3}$. By this approximation the mean square error in sine cosine values are $0.0168 \%$ which is insignificant and does not affect the accuracy of the system performance.

There are two modules for the designing of the scale free CORDIC processor, the Coordinate calculation modules and shift calculation modules.

(i)Coordinate Calculation Modules:-The expansion of the third order Taylor series approximation is as in equations.

$x i+1=\left(1-\frac{\alpha i^{2}}{! 2}\right) x i-\left(\alpha i-\frac{\alpha i^{3}}{! 3}\right) y i$
$y i+1=\left(\alpha i-\frac{\alpha i^{3}}{! 3}\right) x i+\left(1-\frac{\alpha i^{2}}{! 2}\right) y i$

Assuming $\alpha \mathrm{i}=2^{-\mathrm{si}}$ and approximation of factorial, the above equation can be simplified to

$$
\begin{aligned}
& x i+1=\left(1-\frac{2^{-2 s i}}{2}\right) x i-\left(2^{-2 s i}-\frac{2^{-3 s i}}{2^{3}}\right) y i \\
& y i+1=\left(2^{-2 s i}-\frac{2^{-3 s i}}{2^{3}}\right) x i+\left(1-\frac{2^{-2 s i}}{2}\right) y i \\
& x i+1=\left(1-2^{-(2 s i+1)}\right) x i-\left(2^{-2 s i}-2^{-(3 s i+3)}\right) y i \\
& y i+1=\left(2^{-2 s i}-2^{-(3 s i+3)}\right) x i+\left(1-2^{-(2 s i+1)}\right) y i
\end{aligned}
$$

The above equations are used for calculation for the $\mathrm{x}$ and $\mathrm{y}$ coordinates. The output of this module will be used as input to the next clock cycle and the iteration continues until the counter is reset to zero. 
(ii)Shift Calculation module:-The word length is fixed up to $\mathrm{N}=16 . \mathrm{M}$ is the location of the most significant bit 1 first of the input angle $\theta \mathrm{i}$. By the help of identification of the location of the first (1) bit of the input string angle $(\theta)$ we find out the shift index value for next calculation of the coordinate. $\alpha$ is the first elementary angle $=0.25$. Total no of iteration for third order taylor series is 7 and shift calculation module is used to get the shift index (si) parameter.

\section{CORDIC BASED HIGH PASS FIR}

\section{FILTER}

We have chosen an arbitrary frequency response equation of a High Pass FIR filter [12] is given by equation.

$H\left(e^{j w}\right)=0.75-0.45 \cos w-0.31 \cos 2 w-0.15 \cos 3 w$ In this paper we have find out the magnitude value and response of the filter. By using the CORDIC algorithm find out the cosine value of the given angle. And then by using adder and sub-tractor find out the magnitude value.

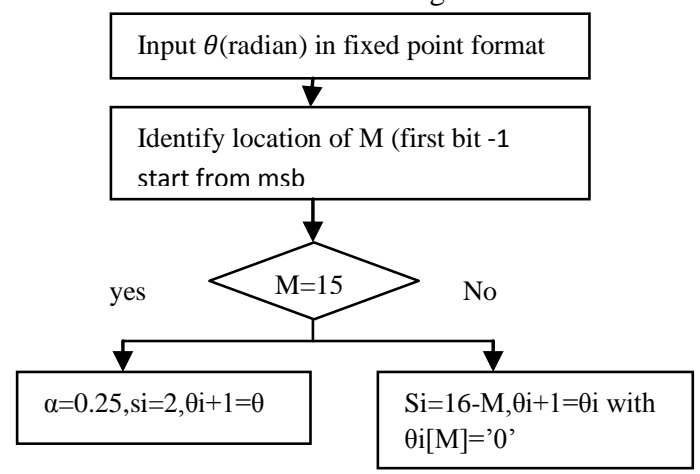

Fig 1: Flow Chart for Scale Free CORDIC Algorithm

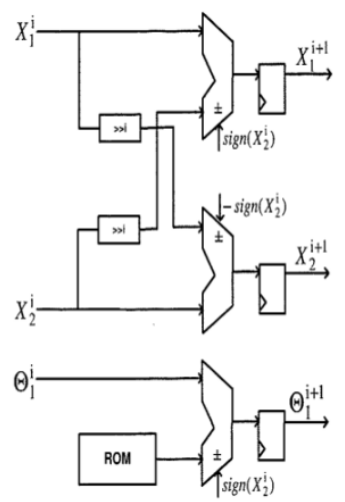

Fig 2: Folded Architecture

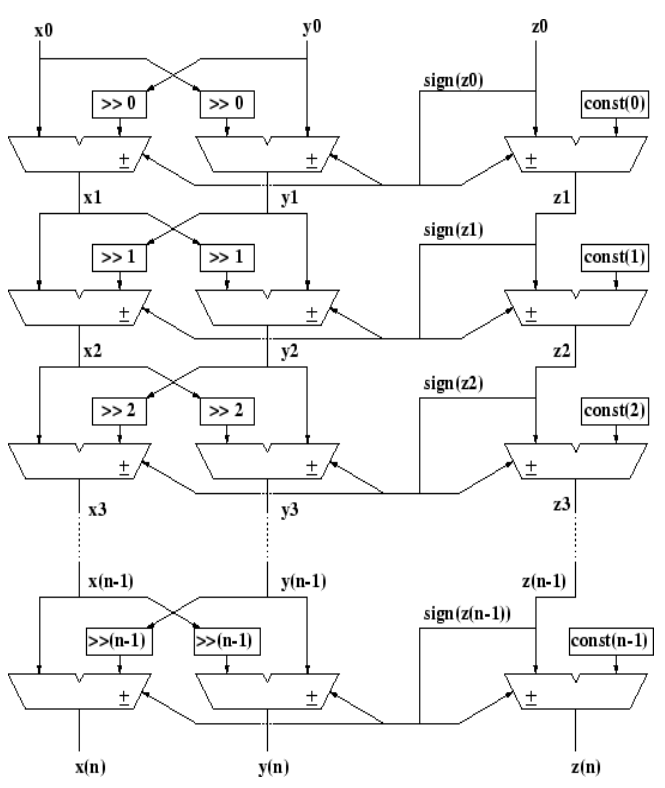

Fig 3: Unfolded Architecture

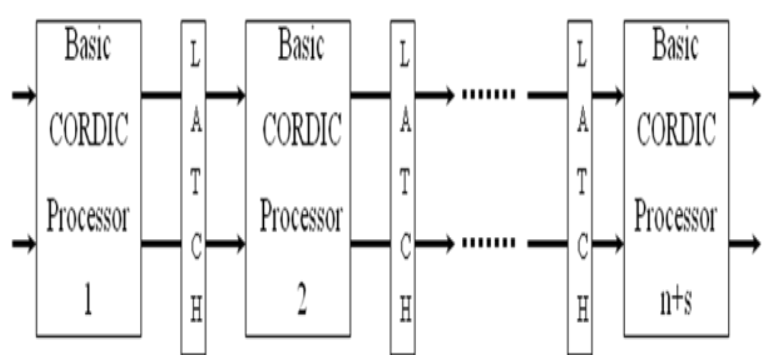

Fig 4: Pipelined Architecture

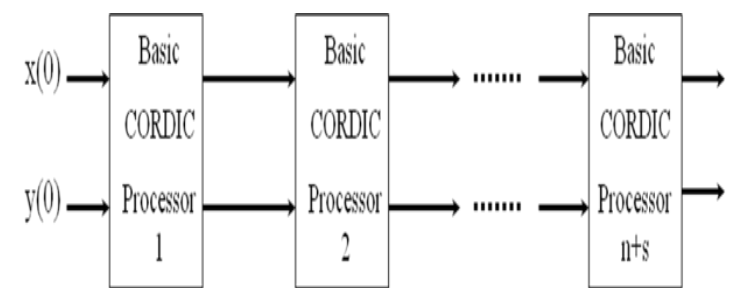

Fig 5: Parallel Architecture

\section{RESULTS}

(a)Sine cosine Generator by using typical CORDIC Algorithm

$\mathrm{x}[15: 0]=9945(\mathrm{dec})$

$1=2^{\wedge} 14=16384$

$\mathrm{x}[15: 0]=0.607=9945$

$\mathrm{y}[15: 0]=0=0$

$z[15: 0]=10(\mathrm{dec})=10 \mathrm{degree}$

$\mathrm{x}($ output $)=\cos \left(10^{\circ}\right)=0.98$ (actual value $)$

Obtained value $=16163(\mathrm{dec})$

$16163 / 16384=0.98$

Percentage Error in cos value

$=($ Actual Value-Obtained Value/Actual Value $) * 100$

$=(0.98-0.98) * 100 / 0.98=0 \%$.

$\mathrm{y}($ output $)=\sin \left(10^{\circ}\right)=0.174($ actual value $)$

Obtained value $=2644(\mathrm{dec})$ 
$2644 / 16384=0.161$

Percentage Error in sin Value $=(0.174-$

$0.161) * 100 / 0.174=7.47 \%$

Timing Summary- (Virtex-4) Speed Grade: -12

Minimum period: $30.988 n$ s (Maximum Frequency:

$32.271 \mathrm{MHz}$

Minimum input arrival time before clock: $37.546 \mathrm{~ns}$

Maximum output required time after clock: $35.760 \mathrm{~ns}$

Maximum combinational path delay: $46.598 \mathrm{~ns}$

\section{(b) High Pass FIR Filter designing by using typical CORDIC Algorithm}

At angle $\theta^{\circ}=10$,

$\mathrm{H}\left(\mathrm{e}^{\mathrm{jw}}\right)=-1893(\mathrm{dec})-$ obtained value

$$
=-1893 / 16384=-0.11
$$

Actual Value $=-0.109$

Percentage Error in Filter output value

$=($ Actual Value-Obtained Value/Actual Value $) * 100$

$=(-0.109+0.11) * 100 / 0.109=0.009 \%$.

In this design we obtained the results for angles from $0^{\circ}$ to $29^{\circ}$.

Timing Summary-(Virtex-4) Speed Grade: -12

Minimum period: 32.639 ns (Maximum Frequency:

$30.638 \mathrm{MHz}$

Minimum input arrival time before clock: $41.321 \mathrm{~ns}$

Maximum output required time after clock: $95.742 \mathrm{~ns}$

Maximum combinational path delay: $102.875 \mathrm{~ns}$

\section{(c)Sine cosine Generator by using Scale free}

\section{CORDIC Algorithm}

Angle $35^{\circ}=9 \mathrm{c} 61$ (hex) $=40033(\mathrm{dec})$

$\mathrm{x}($ output $)=\cos \left(35^{\circ}\right)=3463($ hex $)=13411(\mathrm{dec})$

$=0.81854$ (obtained value)

Actual Value $=\cos \left(35^{\circ}\right)=0.891$.

Percentage Error in cos value =
$(0.891-0.81854) * 100 / 0.891=8.13 \%$

$\mathrm{y}($ output $)=\sin \left(35^{\circ}\right)=24 \mathrm{c} 6($ hex $)=9414(\mathrm{dec})$

$=0.5745$ (obtained value)

Actual Value $=\sin \left(35^{\circ}\right)=0.5735$.

Percentage Error in sin value $=(0.5735-0.5745) * 100 / 0.5735$

$=-0.17 \%$

Timing Summary-(Virtex-4) Speed Grade: -12

Minimum period: 10.849 ns (Maximum Frequency:

$92.178 \mathrm{MHz})$

Minimum input arrival time before clock: $5.909 \mathrm{~ns}$

Maximum output required time after clock: $3.879 \mathrm{~ns}$

Maximum combinational path delay: No path found

(d)High Pass FIR Filter designing by using Scale free CORDIC Algorithm

At angle $\theta^{\circ}=10$

$\mathrm{H}\left(\mathrm{e}^{\mathrm{jw}}\right)=-1873(\mathrm{dec})-$ obtained value

$=-1873 / 16384=-0.11$

Actual Value $=-0.109$.

Percentage Error in Filter output value

$=($ Actual Value-Obtained Value/Actual Value $) * 100$

$=(-0.109+0.11) * 100 / 0.109=0.009 \%$.

In this design we obtained the results for angles from $0^{\circ}$ to $15^{\circ}$.

Timing Summary (Virtex-4) Speed grade $=-12$

Minimum period: $11.545 \mathrm{~ns}$ (Maximum Frequency: $86.618 \mathrm{MHz})$

Minimum input arrival time before clock: $6.859 \mathrm{~ns}$

Maximum output required time after clock: $44.112 \mathrm{~ns}$

Maximum combinational path delay: No path found

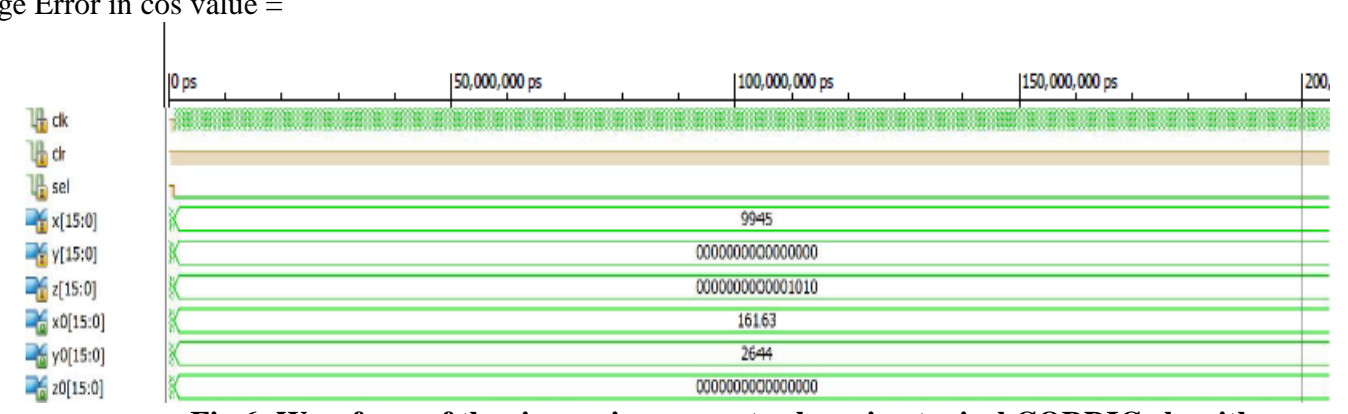

Fig 6: Waveform of the sine cosine generator by using typical CORDIC algorithm

Thick

Ther

7his sel

Dif $2 n[15: 0]$

ZWh $h[15: 0]$

$\nabla$ ini[15:0]

$\nabla_{\mathrm{yin}}[15: 0]$

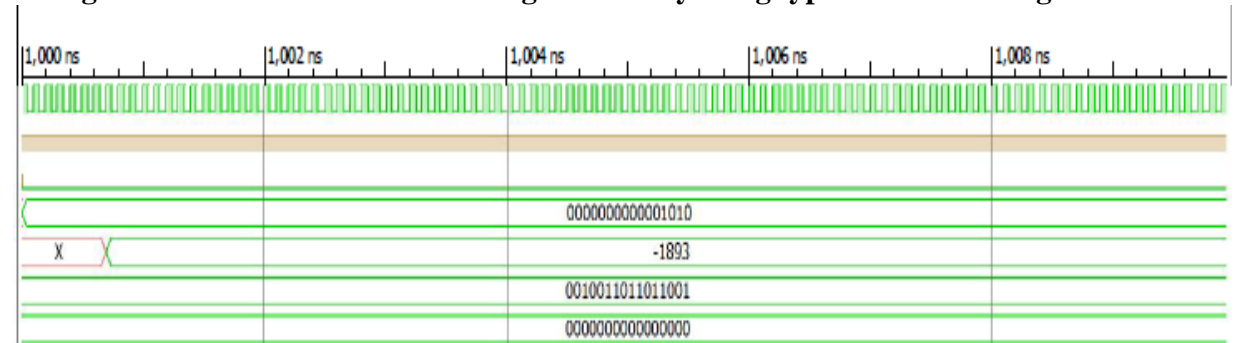

Fig 7: Waveform of the FIR Filter by using typical CORDIC algorithm 


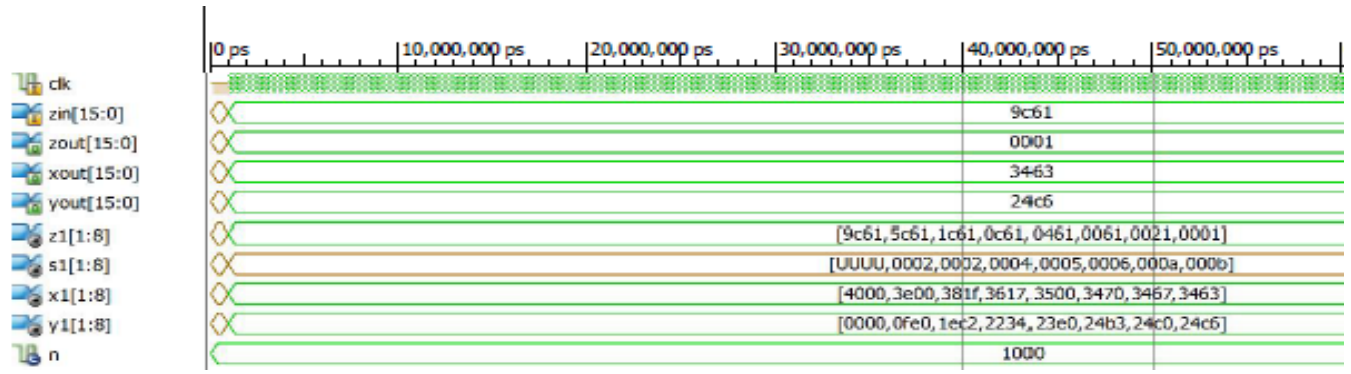

Fig 8: Waveform of the sine cosine generator by using scale free CORDIC algorithm

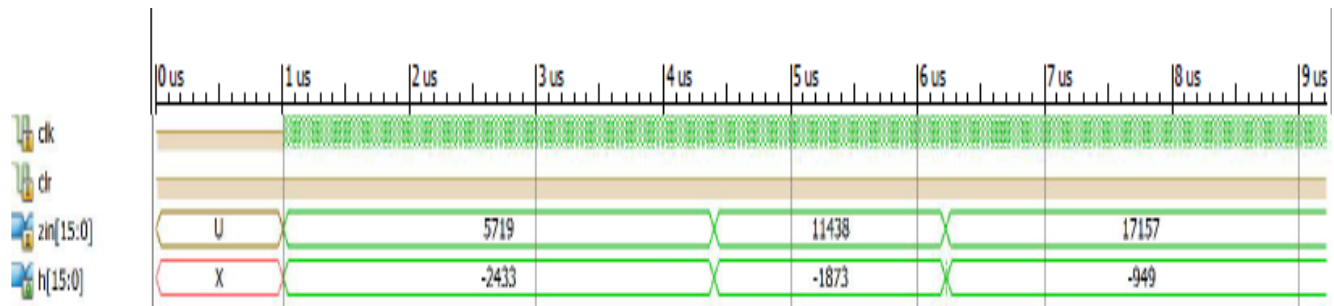

Fig 9: Waveform of sine cosine generator by using scale free CORDIC algorithm

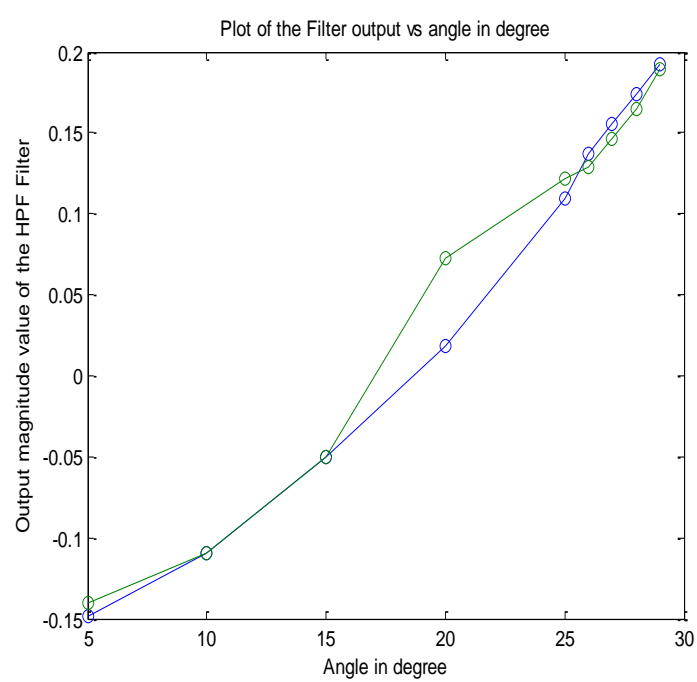

Fig 10(a): Plot of Filter output vs angle in degree (By using typical CORDIC algorithm)

Table1: Hardware Utilization of Sine cosine generator

\begin{tabular}{|c|c|c|c|c|}
\hline Algorithm & $\begin{array}{l}\text { Device } \\
\text { Parameter }\end{array}$ & $\begin{array}{l}\text { No of } \\
\text { Usage }\end{array}$ & $\begin{array}{l}\text { No of } \\
\text { Available }\end{array}$ & Utilization \\
\hline \multirow{4}{*}{$\begin{array}{c}\text { Typical } \\
\text { CORDIC } \\
\text { Algorithm }\end{array}$} & $\begin{array}{c}\text { No of Slice } \\
\text { Register }\end{array}$ & 168 & 71,680 & $1 \%$ \\
\hline & $\begin{array}{c}\text { No of Slice } \\
\text { LUTs }\end{array}$ & 910 & 71,680 & $1 \%$ \\
\hline & $\begin{array}{c}\text { No of } \\
\text { bonded } \\
\text { IOB } \\
\end{array}$ & 99 & 768 & $12 \%$ \\
\hline & $\begin{array}{l}\text { No of } \\
\text { BUFG }\end{array}$ & 1 & 32 & $3 \%$ \\
\hline \multirow{4}{*}{$\begin{array}{c}\text { Scale-free } \\
\text { CORDIC } \\
\text { Algorithm }\end{array}$} & $\begin{array}{c}\text { No of Slice } \\
\text { Register }\end{array}$ & 780 & 71,680 & $1 \%$ \\
\hline & $\begin{array}{c}\text { No of Slice } \\
\text { LUTs }\end{array}$ & 3,865 & 71,680 & $5 \%$ \\
\hline & $\begin{array}{c}\text { No of } \\
\text { bonded } \\
\text { IOB } \\
\end{array}$ & 65 & 768 & $8 \%$ \\
\hline & $\begin{array}{l}\text { No of } \\
\text { BUFG }\end{array}$ & 1 & 32 & $3 \%$ \\
\hline
\end{tabular}

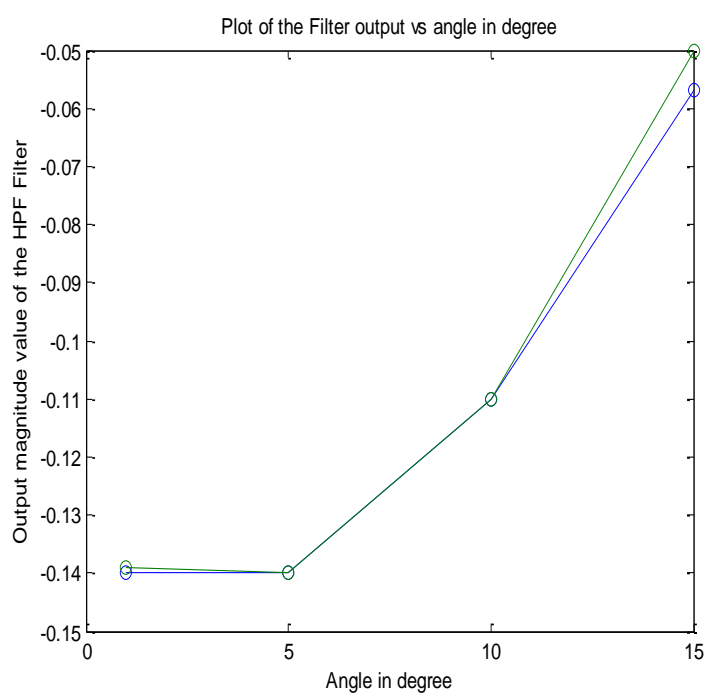

Fig 10(b): Plot of Filter output vs angle in degree (By using scale free CORDIC algorithm)

Table2: Hardware Utilization of High Pass FIR Filter

\begin{tabular}{|c|c|c|c|c|}
\hline Algorithm & $\begin{array}{l}\text { Device } \\
\text { Parameter }\end{array}$ & $\begin{array}{l}\text { No of } \\
\text { Usage }\end{array}$ & $\begin{array}{l}\text { No of } \\
\text { Available }\end{array}$ & Utilization \\
\hline \multirow{4}{*}{\begin{tabular}{|l} 
Typical \\
CORDIC \\
Algorithm
\end{tabular}} & $\begin{array}{l}\text { No of Slice } \\
\text { Register }\end{array}$ & 479 & 71,680 & $1 \%$ \\
\hline & $\begin{array}{l}\text { No of Slice } \\
\text { LUTs } \\
\end{array}$ & 3,354 & 71,680 & $4 \%$ \\
\hline & $\begin{array}{l}\text { No of } \\
\text { bonded } \\
\text { IOB }\end{array}$ & 27 & 768 & $3 \%$ \\
\hline & $\begin{array}{l}\text { No of } \\
\text { BUFG }\end{array}$ & 1 & 32 & $3 \%$ \\
\hline \multirow{4}{*}{\begin{tabular}{|l|} 
Scale-free \\
CORDIC \\
Algorithm
\end{tabular}} & $\begin{array}{l}\text { No of Slice } \\
\text { Register }\end{array}$ & 2146 & 71,680 & $2 \%$ \\
\hline & $\begin{array}{l}\text { No of Slice } \\
\text { LUTs }\end{array}$ & 12,143 & 71,680 & $16 \%$ \\
\hline & $\begin{array}{l}\text { No of } \\
\text { bonded } \\
\text { IOB }\end{array}$ & 34 & 768 & $4 \%$ \\
\hline & $\begin{array}{l}\text { No of } \\
\text { BUFG }\end{array}$ & 1 & 32 & $3 \%$ \\
\hline
\end{tabular}


Table3: Comparison of the designing of sine cosine generator based on typical CORDIC Algorithms and scale free CORDIC Algorithm

\begin{tabular}{|l|l|l|l|}
\hline & $\begin{array}{c}\text { Power } \\
\text { Consumption }\end{array}$ & Frequency & $\begin{array}{l}\text { Combinational } \\
\text { path delay }\end{array}$ \\
\hline $\begin{array}{l}\text { Typical } \\
\text { CORDIC }\end{array}$ & $0.850 \mathrm{~W}$ & $32.271 \mathrm{MHz}$ & $46.598 \mathrm{~ns}$ \\
$\begin{array}{l}\text { Algorithm } \\
\text { based sine } \\
\text { cosine } \\
\text { generator }\end{array}$ & & & \\
\hline $\begin{array}{l}\text { Scale free } \\
\text { CORDIC }\end{array}$ & $0.691 \mathrm{~W}$ & $92.178 \mathrm{MHz}$ & NIL \\
$\begin{array}{l}\text { Algorithm } \\
\text { based sine } \\
\text { cosine } \\
\text { generator }\end{array}$ & & & \\
\hline
\end{tabular}

Table4: Comparison of the designing of High Pass FIR Filter based on typical CORDIC Algorithms and scale free CORDIC Algorithm

\begin{tabular}{|l|l|l|l|}
\hline & \multicolumn{1}{|c|}{$\begin{array}{c}\text { Power } \\
\text { Consumption }\end{array}$} & Frequency & $\begin{array}{l}\text { Combinational } \\
\text { path delay }\end{array}$ \\
\hline $\begin{array}{l}\text { Typical } \\
\text { CORDIC } \\
\text { Algorithm } \\
\text { based sine } \\
\text { cosine } \\
\text { generator }\end{array}$ & $0.660 \mathrm{~W}$ & $30.638 \mathrm{MHz}$ & $102.875 \mathrm{~ns}$ \\
\hline $\begin{array}{l}\text { Scale free } \\
\text { CORDIC } \\
\text { Algorithm } \\
\text { based sine } \\
\text { cosine } \\
\text { generator }\end{array}$ & $0.769 \mathrm{~W}$ & $86.618 \mathrm{MHz}$ & NIL \\
\hline
\end{tabular}

\section{CONCLUSION}

In these observations we notice that scaling free CORDIC algorithm based two different designs have higher frequency, less time period and low power consumption as compared to typical CORDIC algorithm based designs.

Scaling free CORDIC Algorithm based sine cosine generator and FIR HPF has less (i) input arrival time before clock (ii) output required time after clock (iii) combinational path delay as compared to typical CORDIC algorithm. So the Scaling free CORDIC algorithm gives more advantages than typical CORDIC algorithm.

But the occupied space of scaling free CORDIC algorithm based designs is slightly more than the typical CORDIC algorithm based designs. The typical CORDIC algorithm has the range of target angle for the calculation of sine cosine generator is from $0^{\circ}$ to $90^{\circ}$, and for scaling free CORDIC algorithm the range of convergence is from $0^{\circ}$ to $45^{\circ}$. So in case of conventional CORDIC algorithm based filter design has the plot of the output magnitude vs angle variation from $0^{\circ}$ to $29^{\circ}$ and in case of scale free CORDIC algorithm based filter design has the plot of the magnitude vs angle variation from $0^{\circ}$ to $15^{\circ}$. The scale free CORDIC algorithm based high pass FIR filter has more closer results to the calculated results as compared to the conventional CORDIC algorithm based high pass FIR filter.

\section{REFERENCES}

[1] J.E.Volder, "The CORDIC trigonometric computing techniques" IRE Transactions on Electronic Computers, vol 8, no.3,pp. 330-334,1959

[2] J.S.Walther, "A unified algorithm for elementary functions", in proceedings of AFIPS Spring Joint Computer Conference, pp.379-385, May 1971.

[3] Y.H.HU, "CORDIC based VLSI architecture for digital signal processing," IEEE signal processing Magazine, vol.9, no.3, pp16-35, 1992.

[4] Ray Andraka, Andraka consulting group, "A Survey of CORDIC Algorithms for FPGA based computers", in Proceedings of the $6^{\text {th }}$ ACM/SIGDA International

Symposium on Field Programmable Gate Arrays

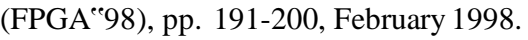

[5] J.E.Volder, "The birth of CORDIC", Journal of VLSI Signal Processing, Vol.25, no.2, pp.101- 105, 2000.

[6] J.S.Walther, "The story of Unified CORDIC", Journal of VLSI signal processing, vol.25, no.2, pp -107-112, 2000.

[7] Pramod. K. Meher, Javier VALLS, Tso Bing Juang, K.Sridharan, Koushik Maharatna, "50 years of CORDIC Algorithms, Architectures and Applications", IEEE Transactions on Circuits and System -1: Regulars Papers, vol.56, no.9. September 2009.

[8] B.Laxmi and A.S.Dhar, "CORDIC Architectures: A Survey", Hindawai Publishing Corporation VLSI Design Volume 2010, Article ID 794891, 19 Pages.

[9] B.Laxmi, A.S.Dhar, "VLSI architecture for low latency radix-4 CORDIC" Computers and Electrical Engineering, Vol-37(2011), pp-1032-1042.

[10] Supriya Aggarwal and Kavita Khare, "RedesignedScale Free CORDIC Algorithm Based FPGA Implementation of Window Functions to Minimize Area and Latency" Hindawi Publishing Corporation ,International Journal of Reconfigurable Computing Volume 2012,Article ID 185784,8 pages.

[11] A.S.N.Mokhtar, M.B.I Reaz,K.Chellappan and M.A Mohd Ali, "Scaling Free CORDIC Algorithm Implementation of Sine and Cosine Function .Proceedings of the World Congress on Engineering 2013 Vol II, WCE 2013, July 3-5, London, U.K

[12] Nutan Das, Swarnaprabha Jena , Siba Kumar Panda, "FPGA Implementation of Angle Generator for CORDIC Based High pass FIR Filter Design", IOSR Journal of Electronics and Communication Engineering(IOSRJECE) e-ISSN: 2278-2834,p-ISSN: 2278-8735, pp-01-11

[13] Anita Jain, Kavita Khare, Supriya Aggarwal, "A Novel Scaling Free Vectoring CORDIC and its FPGA implementation", International Journal of Computer Applications (0975-88875) volume 63- No. 14,February 2013. 